\title{
Potentially Inappropriate Prescribing of Benzodiazepines for Older Adults and Risk of Falls During a Hospital Stay: A Descriptive Study
}

\author{
Stacy Ackroyd-Stolarz, Neil J MacKinnon, Ingrid Sketris, and Brenda Sabo
}

\begin{abstract}
Background: Falls have been identified as a potential adverse event associated with the administration of psychotropic medications to older patients.

Objective: The objective of this exploratory study was to examine the association between potentially inappropriate prescribing of benzodiazepines, as defined by the Beers criteria, by older adults (at least 65 years of age) and the risk of having a fall during acute inpatient care.

Methods: This 1-year retrospective cross-sectional study of discharges from a tertiary care hospital in Halifax, Nova Scotia, used pharmacy data to identify the prescription of benzodiazepines listed in the updated Beers criteria as being associated with an increased risk of falls. These data were linked with information on in-hospital falls from occurrence report forms.

Results: For 5831 (58.1\%) of the 10044 discharges, the patient had received a prescription for at least one benzodiazepine during the hospital stay. A total of 574 falls were reported (for 374 patients), and $226(39.4 \%)$ of the falls resulted in an injury. According to the Beers criteria, for $936(9.3 \%)$ of the discharges, the patient had received a prescription for at least one potentially inappropriate benzodiazepine. However, there was no statistically significant difference between patients with a prescription for a potentially inappropriate benzodiazepine and those receiving an appropriate or no benzodiazepine in terms of occurrence of falls ( $4.5 \%$ versus $3.8 \%, p=0.30)$ or fall-related injuries $(2.6 \%$ versus $1.8 \%, p=0.08)$. The median length of stay was about 3 days longer for the former group ( 9 versus 6 days, $p<0.001$ ).

Conclusions: The findings from the current study do not support use of the Beers criteria related to benzodiazepines alone for identifying patients at risk of falls or injuries.
\end{abstract}

Key words: potentially inappropriate medications, benzodiazepines, fall-related injuries, older adults, acute care, Beers criteria

Can J Hosp Pharm 2009;62(4):276-283

\section{RÉSUMÉ}

Contexte : Les chutes comptent parmi les effets indésirables potentiels associés à l'administration de psychotropes à des patients âgés.

Objectif : L'objectif de cette étude exploratoire était d'examiner le lien entre la prescription potentiellement inappropriée de benzodiazépines, selon les critères de Beers, chez les personnes âgées (au moins 65 ans) et le risque de chute durant une hospitalisation pour soins de courte durée.

Méthodes : Cette étude rétrospective transversale d'une durée d'un an des congés d'un hôpital de soins tertiaires de Halifax, en NouvelleÉcosse, a fait appel aux données de la pharmacie pour retracer la prescription de benzodiazépines répondant aux critères actualisés de Beers comme étant associé à un risque de chute accru. Ces données ont ensuite été mises en parallèle avec l'information sur les chutes survenues à l'hôpital tirée des formulaires de déclaration d'incidents.

Résultats : À l'égard de 5831 (58,1\%) des 10044 congés, le patient avait reçu une ordonnance pour au moins une benzodiazépine durant son séjour à l'hôpital. Un total de 574 chutes ont été déclarées (pour 374 patients), et $226(39,4 \%)$ de celles-ci ont causé une blessure. D'après les critères de Beers, au moins une benzodiazépine potentiellement inappropriée a été prescrite au patient à l'égard de $936(9,3 \%)$ des congés examinés. Il n’y avait cependant aucune différence statistiquement significative dans la survenue des chutes $(4,5 \%$ contre $3,8 \%, p=0,30)$ ou dans les blessures associées aux chutes $(2,6 \%$ contre $1,8 \%, p=0,08)$ entre le groupe de patients ayant reçu une ordonnance pour une benzodiazépine potentiellement inappropriée et celui ayant reçu une benzodiazépine appropriée ou n'en n'ayant pas reçu. La durée médiane du séjour à l'hôpital était d'environ trois jours de plus pour le premier groupe ( 9 contre 6 jours, $p<0,001$ ).

Conclusions : Les résultats de cette étude ne corroborent pas l'emploi des critères de Beers associés aux benzodiazépines seules pour dépister les patients à risque de chutes ou de blessures.

Mots clés : médicaments potentiellement inappropriés, benzodiazépines, blessures par chute, personnes âgées, soins de courte durée, critères de Beers

[Traduction par l'éditeur] 


\section{INTRODUCTION}

$\mathrm{U}$ nintentional falls account for a significant proportion of injury-related morbidity and mortality, particularly in the aged population. ${ }^{1}$ About one-third of elderly people fall each year, and of those, half will sustain a minor injury, and up to $25 \%$ will sustain a more serious injury. ${ }^{2}$ Fall-related injuries can accelerate functional decline and admission to a nursing home. ${ }^{3,4}$ Admission to hospital poses unique risks of falling in older adults. In addition to the consequences of immobilization, the unfamiliar environment, factors arising from the acute illness, and the effects of the treatment may all place older persons at higher risk of a fall during a hospital stay. ${ }^{5,6}$

The use of medications is an important and potentially modifiable risk factor for falls in older adults. Given the complex, multifactorial nature of the risk of falling, the establishment of a causal relationship between medication use and falls in older adults is challenging. Various classes of medications have been examined in the literature, but the weight of the evidence suggests that those most commonly associated with falls are psychotropic medications, particularly benzodiazepines. ${ }^{7-9}$ Monane and Avorn ${ }^{10}$ suggested that psychotropic medications contribute to falls through their effect on balance, corrective responses, and postural hypotension. They also noted that the effect of medications may be altered by metabolic changes and diminished renal function in older patients. In addition, there is evidence that the total number of medications taken is associated with the risk of falls. ${ }^{7,11}$

Use of prescription medications is disproportionately higher among older adults. ${ }^{12}$ The challenges of appropriate drug therapy for the aging population have long been recognized. ${ }^{13,14}$ In 2001, the Canadian Society of Hospital Pharmacists (CSHP) developed a position statement on the importance of monitoring drug therapy in older patients, which aimed at achieving the optimal therapeutic outcome while minimizing the potential for adverse effects. ${ }^{15}$ In the United States, a set of consensus-based explicit criteria for determining potentially inappropriate medication use in older adults was first developed in 1991 by Beers and others ${ }^{16}$ and was updated in $2003 .{ }^{17}$ Medications were included on the list if the potential risks were thought to outweigh the potential benefits. The Beers criteria cover potentially inappropriate medications and/or doses of medications, as well as medications that are contraindicated for specific diseases or under specific conditions. The current study focuses on the first of these 2 categories.

Beers and others ${ }^{16,17}$ identified 3 criteria for benzodiazepine use that specifically relate to an increased risk of falls and fractures through prolonged sedation or increased sensitivity to benzodiazepines: use of flurazepam, use of long-acting benzodiazepines (e.g., chlordiazepoxide), and use of short- acting benzodiazepines above specified daily doses (lorazepam > $3 \mathrm{mg}$, oxazepam $>60 \mathrm{mg}$, alprazolam $>2 \mathrm{mg}$, temazepam > $15 \mathrm{mg}$, and triazolam $>0.25 \mathrm{mg}$ ). A number of studies have examined the association between different types of benzodiazepines and the risk of fall-related injuries for patients who have been admitted to hospital. ${ }^{78,18}$ However, to the authors' knowledge, the current study is the first performed in an acute care setting in Canada that examines this association specifically for potentially inappropriate benzodiazepines, as identified by the Beers criteria. The primary objective of this exploratory study was to examine the association between the potentially inappropriate prescribing of benzodiazepines listed in the updated Beers criteria and the risk of a fall in the acute care hospital setting.

\section{METHODS \\ Design, Patients, and Setting}

This retrospective cross-sectional study included all hospital discharges for patients 65 years of age or older who were admitted to the Queen Elizabeth II Health Sciences Centre between June 1, 2003, and May 31, 2004, and who received care in an acute medical or surgical inpatient unit during their hospital stay. The study duration was set at 1 year to control for potential selection bias and seasonal variation in hospital admissions and to ensure an adequate sample size. With about 1000 beds (including an annual average of 203 medical and 208 surgical beds), the Queen Elizabeth II Health Sciences Centre is the largest academic health sciences facility for adults in Atlantic Canada. In addition to providing primary health care services to the local community, the hospital provides tertiary care for the region. At the time of the study, the hospital did not have any fall-prevention programs in place, nor were any tools to screen for the risk of falls used in the acute care settings under study.

\section{Data Sources}

Administrative and clinical data from 3 routinely collected sources were used for the study. The Quality and Decision Support division of the hospital provided basic demographic and clinical data for all of the hospital stays. The clinical data included information about the diagnosis considered most responsible for the hospital admission, according to the International Classification of Diseases version 10 (ICD-10$\mathrm{CA})$, grouped into broad diagnostic categories. ${ }^{19,20}$ Data on inhospital drug utilization for the study patients were obtained from the hospital's pharmacy information system (BDMRxTFC version 4.00, BDM Information Systems Ltd, Saskatoon, Saskatchewan), which was housed in the Pharmacy Department at the Queen Elizabeth II Health Sciences Centre. This database identified all patients with an in-hospital 
prescription for any of the benzodiazepines meeting the Beers criteria, including all doses of short-acting benzodiazepines. These data did not identify the prescribing physician or the unit care team for individual patients. Finally, electronic data on all falls (with or without injury) were obtained from the institution's occurrence reporting system. The occurrence report form used by the hospital at the time of the study was organized according to type of occurrence, namely, related to a procedure, a fall, equipment, medication, or the patient's behaviour (e.g., aggression). In the section on falls, information was collected on the location of the fall, use of an assistive device (e.g., cane), use of hip protectors, patient's footwear, environmental conditions, restrictions (e.g., visual impairment), and type of injury sustained. No information was collected on the medications that the patient was taking at the time of the fall. Staff in the division of Risk Management rated each fall according to a standardized approach, to determine the amount of harm that the patient experienced.

The exposure of interest was in-hospital prescription of any of the potentially inappropriate benzodiazepines identified by the Beers criteria. Potentially inappropriate benzodiazepine prescribing for each discharge was determined on the basis of all benzodiazepine prescriptions during the admission. For patients who had received prescriptions for more than one benzodiazepine during a hospital stay (concurrently or not), the presence of any single potentially inappropriate drug during the hospital stay led to categorization as potentially inappropriate prescribing. For the short-acting benzodiazepines, only prescriptions involving a dose greater than the daily dose listed in the criteria were considered potentially inappropriate. Information about the medications that were administered by a nurse could only be captured from a hard copy of the medication record on each patient's medical chart, as electronic medication administration records were not available at the time of the study. It was beyond the scope and resources of the study to conduct extensive chart reviews to determine if any patients had received as-needed (PRN) medications.

The primary outcome of interest was any fall recorded in the institutional occurrence reporting system. Any injuries documented in the occurrence report form for any such fall were also identified.

The study received approval from the Capital District Health Authority Research Ethics Board in September 2004.

\section{Data Analysis}

Data for individual patients from the 3 data sources were linked by means of a unique study number. The differences between groups (i.e., with or without potentially inappropriate benzodiazepine prescribing) were compared using the $\chi^{2}$ test for categorical data, an unpaired $t$ test for normally distributed continuous data, and a Mann Whitney $U$ test for nonparametric data. Two-sided $p$ values are reported, with values less than 0.05 considered statistically significant. Missing data were retained as such. Although multivariate logistic regression analyses were performed, the results are not reported because the adjusted effects were similar to the unadjusted estimates. Of greater importance, the administrative data were of insufficient quality and detail to adequately control for other factors that might have contributed to the falls (e.g., comorbidities), given the multifactorial nature of the risk of falls. All analyses were conducted with STATA statistical software (version 7, STATA Corp, College Station, Texas).

\section{RESULTS}

Between June 1, 2003, and May 31, 2004, there were a total of 10044 discharges for 8976 patients 65 years of age or older who had received acute medical or surgical care in the study hospital. Some individuals had more than one hospital stay during the 1-year period, and the data were analyzed in terms of the total number of discharges. At least one benzodiazepine was prescribed in hospital for 5831 (58.1\%) of the discharges. The average duration of the prescription was 7.1 days (standard deviation [SD] 13.1). The most common diagnoses were cardiovascular disease (29.6\%) and cancer (12.7\%) (Table 1).

\section{Potentially Inappropriate Benzodiazepine Prescribing}

In total, 11544 prescriptions for benzodiazepines were identified for the 10044 discharges. The electronic version of each prescription was reviewed to determine if the medication was one of those listed in the Beers criteria. Of the 11544 prescriptions, $30(0.26 \%)$ were for flurazepam and 373 (3.2\%) were for a long-acting benzodiazepine, of which diazepam was the most common (332 [89.0\%] of the 373 prescriptions). These drugs were considered potentially inappropriate according to the criteria. Most of the prescriptions (11 141 or $96.5 \%)$ were for short-acting benzodiazepines, of which lorazepam was most common (7286 [65.4\%] of the 11141 prescriptions). The Beers criteria stipulate a maximum daily dose for short-acting benzodiazepines, with doses above the maximum considered potentially inappropriate. In the electronic records, some of the prescriptions for short-acting benzodiazepines indicated a dose range, rather than a specific dose. If the prescriptions for short-acting benzodiazepines that indicated a range of doses were assumed to have been filled at the lowest dose (best-case scenario), a total of 1016 (8.8\%) of all benzodiazepine prescriptions (including flurazepam and long-acting benzodiazepines) were potentially inappropriate. If, however, the prescriptions indicating a range of doses were assumed to have been filled at the highest dose (worst-case 
Table 1. Characteristics of Patients, Classified by Appropriateness of Benzodiazepine Therapy

Classification of BZD Therapy; No. (\%) of Patients*

\begin{tabular}{|c|c|c|c|c|c|}
\hline \multirow{2}{*}{$\begin{array}{l}\text { Characteristic } \\
\text { Sex, \% male }\end{array}$} & \multicolumn{2}{|c|}{$\begin{array}{l}\text { Appropriatet BZD } \\
\text { Therapy or No BZD } \\
\text { Therapy }(n=9108)\end{array}$} & \multicolumn{2}{|c|}{$\begin{array}{c}\text { Potentially Inappropriatet } \\
\text { BZD Therapy } \\
(n=936)\end{array}$} & \multirow{2}{*}{$\begin{array}{r}p \text { value } \neq \\
0.010\end{array}$} \\
\hline & 4739 & $(52.0)$ & 528 & $(56.4)$ & \\
\hline Age, mean (SD) (years) & 76.1 & $(7.5)$ & 74.5 & $(6.8)$ & $<0.001$ \\
\hline \multicolumn{6}{|l|}{ Diagnosis§ } \\
\hline Cardiovascular system & 2701 & $(29.7)$ & 269 & $(28.7)$ & 0.56 \\
\hline Cancer & 1152 & $(12.6)$ & 123 & (13.1) & 0.67 \\
\hline Injury-related & 860 & $(9.4)$ & 118 & $(12.6)$ & 0.002 \\
\hline Respiratory system & 607 & $(6.7)$ & 99 & $(10.6)$ & $<0.001$ \\
\hline Digestive system & 648 & $(7.1)$ & 45 & $(4.8)$ & 0.010 \\
\hline Musculoskeletal & 570 & $(6.3)$ & 40 & (4.3) & 0.020 \\
\hline Genitourinary & 524 & (5.8) & 29 & (3.1) & $<0.001$ \\
\hline Mental or behavioural & 104 & $(1.1)$ & 26 & (2.8) & $<0.001$ \\
\hline Nervous system & 140 & $(1.5)$ & 14 & $(1.5)$ & 0.92 \\
\hline Endocrine system & 170 & (1.9) & 7 & $(0.7)$ & 0.010 \\
\hline Other & 1632 & $(17.9)$ & 166 & $(17.7)$ & 0.47 \\
\hline Length of stay, median (IQR) (days) & 6 & $(3-12)$ & 9 & $(4-19)$ & $<0.001$ \\
\hline Any fall & 343 & $(3.8)$ & 42 & $(4.5)$ & 0.30 \\
\hline Any injury & 160 & $(1.8)$ & 24 & $(2.6)$ & 0.08 \\
\hline
\end{tabular}

BZD = benzodiazepine, IQR = interquartile range, SD = standard deviation.

*Unless indicated otherwise.

†According to Beers criteria for BZDs only. ${ }^{16,17}$

‡Groups were compared using the $\chi^{2}$ test for categorical data, an unpaired $t$ test for normally distributed continuous data,

and a Mann-Whitney $U$ test for nonparametric data.

$\S$ Diagnostic category considered to be "most responsible for hospital admission" according to diagnosis-type indicator

of the Canadian Institute for Health Information. ${ }^{19,20}$

scenario), a total of $4621(40.0 \%)$ of all benzodiazepine prescriptions were for drug types or doses considered inappropriate for this age group. From the administrative data sources used for this study, it was possible to determine only the dose prescribed, not the dose that was actually consumed by each patient.

Interestingly, the proportion of potentially inappropriate prescriptions decreased with increasing age: $506(10.7 \%)$ of 4709 discharges involving patients 65 to 74 years of age and 74 (5.3\%) of 1402 discharges involving those 85 years or older $(p<0.001)$. The median length of stay was 3 days longer for those with a potentially inappropriate benzodiazepine prescription $(9$ versus 6 days, $\mathrm{p}<0.001$ ) (Table 1). The proportion who died was also greater in this group: 129 $(13.8 \%)$ of 936 versus $771(8.4 \%)$ of $9108(p<0.001)$. The division of Risk Management attributed one death to a fall-related injury; all other deaths were categorized as "all-cause mortality".

\section{Fall Events}

Three hundred and seventy-four patients (4.2\% of the 8976 patients in this study) had a total of 574 fall events during the study period. Two hundred and eighty $(74.9 \%)$ of these patients had one fall each, and 20 patients (5.3\%) had
4 or more falls. Each patient record represented 1 unique hospital stay $(n=10044)$, and fall status was identified for each record. At least one fall had to have occurred during a unique hospital stay for that stay to be coded as positive for a fall. Eleven patients fell during 2 separate admissions, so the total number of records involving a fall was 385 .

There was no statistically significant difference between patients with a prescription for a potentially inappropriate type or dose of benzodiazepine, as identified by the Beers criteria, and those with a prescription for an appropriate dose and type of benzodiazepine or no benzodiazepine at all in terms of occurrence of a fall $(4.5 \%$ versus $3.8 \%, p=0.30)$ or a fallrelated injury ( $2.6 \%$ versus $1.8 \%, p=0.08$ ) (Table 1 ). Most of the falls occurred in patients' rooms, either at the bedside or in the bathroom or in transit between these 2 locations. Injuries were sustained in 226 (39.4\%) of the 574 falls. Most of the injuries were minor, including abrasions (73 [32.3\%] of the 226 injuries), lacerations (63 [27.9\%]), soreness (49 [21.7\%]), and contusions (24 [10.6\%]). There were 7 fractures (3.1\%). The risk of injury increased with age (injuries being recorded for 60 [1.3\%] of 4709 discharges involving patients 65-74 years of age, 77 [2.0\%] of 3933 discharges involving patients 75-84 years, and 47 [3.4\%] of 1402 discharges involving patients 85 years or older; $p<0.001$ ). 
For $203(35.4 \%)$ of the 574 falls, at least one benzodiazepine had been prescribed for the patient. Of these 203 cases, the prescription was potentially inappropriate in 30 (14.8\%). The most commonly prescribed benzodiazepine was lorazepam (127 [62.6\%] of these 203 falls), followed by a combination of lorazepam and oxazepam $(38$ [18.7\%]) or oxazepam alone (30 [14.8\%]). Only one person had a prescription for flurazepam, and 2 patients had prescriptions for diazepam. The difference in potentially inappropriate prescribing between patients who fell and those who did not fall was nonsignificant $(10.9 \%$ versus $9.3 \%, p=0.27$ ) (Table 2 ).

\section{DISCUSSION}

The rate of falls for a population of adults 65 years of age or older admitted to acute care at the Queen Elizabeth II Health Sciences Centre (374 [4.2\%] of 8976 patients) was consistent with rates reported for other acute care settings. Reported rates for in-hospital falls for patients of all ages have ranged from 2.2 to 7 per 1000 bed-days and from $2 \%$ to $10 \%$ of annual admissions in acute care facilities. ${ }^{18,21,22}$ Only a small proportion of the falls in the current study (7 [1.2\%] of 574 falls) resulted in fractures. Use of the occurrence reporting system to identify falls might not have captured all of the falls that actually took place. For instance, a patient who fell while alone in his or her room might not have reported the fall to the health care staff; conversely, if a fall did not result in injury, staff members might not have officially reported the event using the occurrence reporting system.

With respect to medication use, one striking observation was the high rate of in-hospital prescription for benzodiazepines (58.1\% of all discharges). In a study of predominantly older patients admitted to 58 hospital and university centres in Italy, $23.7 \%$ (1874 of 7908 eligible patients) used benzodiazepines during their hospital admission. ${ }^{18}$ Nurmi-Lüthje and others ${ }^{23}$ used multiple methods, including serum testing and urinalysis, to detect benzodiazepine use in a study of 223 patients with hip fracture at 2 teaching hospitals in Norway. They determined that $51 \%$ of patients had evidence of use of a benzodiazepine or benzodiazepine derivative. The rates were highest among those who had been admitted to hospital from institutional care $(76 \%)$ and lowest for community-dwelling patients (39\%). ${ }^{23}$ The current study included patients admitted from nursing homes and elderly people living in the community. Irrespective of the role of benzodiazepines in the falls analyzed here, the large number of prescriptions for these drugs in the study population was cause for deliberation by the health care organization's Pharmacy Department. As a result of the study, specific standing orders were changed to eliminate any benzodiazepines listed in the Beers criteria (including potentially inappropriate dosages for short-acting agents).

Table 2. Characteristics of Patients, Classified by Falls during Acute Care Stay in a Tertiary Care Hospital

\begin{tabular}{|c|c|c|c|c|c|c|c|}
\hline \multirow{3}{*}{$\begin{array}{l}\text { Characteristic } \\
\text { Potentially inappropriate BZD } \neq\end{array}$} & \multicolumn{6}{|c|}{ Classification by Falls; No. (\%) of Patients* } & \multirow{3}{*}{$\begin{array}{c}\boldsymbol{p} \text { valuet } \\
0.27\end{array}$} \\
\hline & \multicolumn{2}{|c|}{$\begin{array}{c}\text { Overall } \\
(n=10044)\end{array}$} & \multicolumn{2}{|c|}{$\begin{array}{l}\text { With a Fall } \\
(n=385)\end{array}$} & \multicolumn{2}{|c|}{$\begin{array}{l}\text { Without Any Falls } \\
\quad(n=9659)\end{array}$} & \\
\hline & 936 & $(9.3)$ & 42 & $(10.9)$ & 894 & $(9.3)$ & \\
\hline Sex, \% male & 5267 & $(52.4)$ & 203 & $(52.7)$ & 5064 & $(52.4)$ & 0.91 \\
\hline Age, mean (SD) (years) & 75.9 & $(7.5)$ & 79.0 & $(7.7)$ & 75.8 & $(7.4)$ & $<0.001$ \\
\hline \multicolumn{8}{|l|}{ Diagnosis§ } \\
\hline Cardiovascular system & 2970 & $(29.6)$ & 92 & $(23.9)$ & 2878 & $(29.8)$ & 0.013 \\
\hline Cancer & 1275 & $(12.7)$ & 33 & $(8.6)$ & 1242 & $(12.9)$ & 0.013 \\
\hline Injury-related & 978 & $(9.7)$ & 42 & (10.9) & 936 & $(9.7)$ & 0.43 \\
\hline Respiratory system & 706 & $(7.0)$ & 36 & $(9.4)$ & 670 & $(6.9)$ & 0.07 \\
\hline Digestive system & 693 & (6.9) & 13 & (3.4) & 680 & $(7.0)$ & 0.005 \\
\hline Musculoskeletal & 610 & (6.1) & 9 & $(2.3)$ & 601 & $(6.2)$ & 0.002 \\
\hline Genitourinary & 553 & (5.5) & 15 & (3.9) & 538 & $(5.6)$ & 0.16 \\
\hline Mental or behavioural & 130 & (1.3) & 22 & $(5.7)$ & 108 & $(1.1)$ & $<0.001$ \\
\hline Nervous system & 154 & $(1.5)$ & 17 & (4.4) & 137 & $(1.4)$ & $<0.001$ \\
\hline Endocrine system & 177 & $(1.8)$ & 10 & $(2.6)$ & 167 & $(1.7)$ & 0.20 \\
\hline Other & 1798 & $(17.9)$ & 96 & $(24.9)$ & 1702 & $(17.6)$ & $<0.001$ \\
\hline Length of stay, mean (IQR) (days) & 6 & $(3-12)$ & 23 & $(9-57)$ & 6 & $(3-12)$ & $<0.001$ \\
\hline
\end{tabular}

BZD = benzodiazepine, IQR = interquartile range, SD = standard deviation.

*Unless indicated otherwise.

tGroups were compared using the $\chi^{2}$ test for categorical data, an unpaired $t$ test for normally distributed continuous data, and a Mann-Whitney $U$ test for nonparametric data.

$\neq$ According to Beers criteria for BZDs only. ${ }^{16,17}$

$\S$ Diagnostic category considered to be "most responsible for hospital admission" according to diagnosis-type indicator of the Canadian Institute for Health Information. 19,20 
Lorazepam was the most commonly prescribed benzodiazepine in the current study. In a Quebec study of benzodiazepine use, ${ }^{24}$ this drug was also the most frequent initial benzodiazepine prescribed (for $43.7 \%$ of users); however, relative to other types of benzodiazepines, it was associated with a lower risk of injury. In the Quebec study, there were no reports of concurrent prescriptions for lorazepam and oxazepam, ${ }^{24}$ as were observed in the study reported here. In their analysis of adverse outcomes related to the use of psychotropic and narcotic drugs by elderly patients, based on data from the Canadian Study of Health and Aging, Ebly and others ${ }^{25}$ identified a dose-dependent response, with a higher likelihood of an adverse outcome with the use of medications from multiple classes. Computerized decision support tools could help to identify duplicate prescribing from the same therapeutic class.

In their study of adverse drug events associated with the use of a variety of medications listed in the Beers criteria (not just benzodiazepines), Page and others ${ }^{11}$ found no difference in hospital length of stay or mortality. Onder and others ${ }^{26}$ reached the same conclusion from a retrospective cohort study of older patients admitted to 81 geriatric and internal medicine units of hospitals in Italy. In the current study, the findings of longer hospital length of stay and higher mortality rates for those taking potentially inappropriate benzodiazepines must be interpreted with caution, because there were insufficient data for robust risk adjustment. Other factors, such as acuity and severity of illness, may have contributed to these findings. As well, the current study focused only on benzodiazepines identified in the Beers criteria. Further research is needed to confirm the finding and to examine the nature and causes of these differences, as well as to establish the temporal sequence. For example, it is possible that the longer a patient stays in the hospital, the more likely he or she is to receive a prescription that does not follow the Beers criteria. On the other hand, if the use of a potentially inappropriate benzodiazepine contributes to the increased length of stay, then such prescribing has significant resource implications. It was not possible to distinguish between these 2 possibilities from the available data.

The current study included only benzodiazepines listed in the Beers criteria that were in use at the study hospital, which is not an exhaustive list of all medications known to be associated with increased risk of falls. The Beers criteria were selected as a tool to identify potentially inappropriate medications because they are reproducible, easy to follow, and do not require information about the indication for the drug. Despite the fact that they are the most commonly used explicit criteria for examining medication use, the Beers criteria remain somewhat controversial. For example, they are based on literature review and consensus, and not all of the criteria are associated with strong empirical data linking them to harm. Federal regulators in the United States have adopted these criteria for use in long-term care facilities, even though they were not developed for regulatory purposes. ${ }^{27}$ This has led to their widespread acceptance in many US facilities. Yet there is conflicting evidence in the literature examining the effect of potentially inappropriate medications, as identified by the Beers criteria, on patients' outcomes. ${ }^{26,28-30}$

In their systematic review of outcomes associated with medications listed in the Beers criteria, Jano and Aparasu ${ }^{28}$ concluded that the evidence of an association between the use of potentially inappropriate medications and specific outcomes varied by setting, with the strongest evidence available for outcomes related to the hospital stay (e.g., length of stay) in studies of community-dwelling elderly people. Although none of the studies specifically examined falls leading to injury, these authors speculated that fall-related injuries associated with psychotropic medications listed in the Beers criteria might account for the positive association with hospitalization measures such as increase in length of stay. The evidence is inconclusive for studies conducted in nursing homes or hospitals. Medications listed in the Beers criteria were not associated with an increase in mortality in any of the 18 studies that Jano and Aparasu $^{28}$ evaluated. The authors suggested that further research is needed to determine the predictive validity of the criteria in the nursing home and hospital settings, as well as to examine specific adverse events—including falls_-rather than generalized measures. Using data from the 1996 Medical Expenditure Panel Survey in the United States, Fu and others ${ }^{30}$ attempted to quantify the impact of inappropriate medications on the perceived health status of older adults in a nationally representative sample. After adjustment for other confounding factors, those respondents who were using medication(s) listed in the Beers criteria were more likely to report poorer health status. The authors suggested that this result offers at least some support for use of the Beers criteria.

In the current study there was no statistically significant difference in the occurrence of a fall or a fall-related injury between patients with a prescription for a potentially inappropriate type or dose of benzodiazepine, as identified by the Beers criteria, and those receiving appropriate or no benzodiazepines. Given the evidence in the literature linking an increased risk of falls with the use of benzodiazepines ${ }^{7-9}$ and given the large sample size (which was sufficiently powered [> 85\%] to detect a difference between the groups), the lack of a statistically significant difference was surprising. One possible explanation is that there were other factors contributing to falls in these acutely ill patients that could not be adequately controlled for, given the nature of the administrative data (e.g., pre-existing comorbidities, impaired mobility). In other words, the medication alone might not have caused the fall. This would be consistent with our understanding of the multifactorial nature of the risk of falls. Another plausible explanation is that the benzodiazepines listed in the Beers criteria and in use at the 
hospital were not associated with an elevated risk of falls. In their study on the frequency of adverse drug events associated with medications from the Beers criteria, Page and others ${ }^{11}$ concluded that relatively few adverse events were related to the use of these drugs. They reported only one fall-related injury, which appeared to be due to hypotension caused by doxepin, with no such injuries related to the use of benzodiazepines listed in the Beers criteria. ${ }^{11}$

Clearly, there are opportunities to improve the identification of patients who are at risk of falling. In health care settings not designed specifically for older patients (e.g., surgical units), it is important to educate staff about the risk of fall-related injuries and to identify potential fall prevention strategies. Institutions can start with those that address common modifiable risk factors and thereby improve safety for all patients, beginning with units where falls occur more frequently (to the extent that this is not already being done)..$^{31}$ Optimal medication use is one risk reduction strategy common to all patients. The CSHP statement on monitoring drug therapy in older patients reinforces the value of this strategy for more than preventing fall-related injuries. ${ }^{15}$

\section{Limitations}

It was beyond the scope of this exploratory study to obtain a complete medication profile for the entire study population. Therefore, it was not possible to control for the potential effects of other types of medications (e.g., diuretics). It was also not possible to determine the timing of a fall in relation to the benzodiazepine prescription, a limitation that underscores the challenges in establishing a causal relation between medication use and falls, particularly when administrative data sources are used. Furthermore, it was not possible to determine if the benzodiazepines taken by individual patients had been prescribed in hospital or if they continued prescriptions that had been started before the hospital admission. In the absence of electronic medication administration records, it was not possible to review all medical records to determine if PRN medications that were prescribed had actually been administered and consumed. The potential of benzodiazepines to cause other adverse events, such as delirium, was not determined.

\section{Significance}

Although several previous studies in a variety of settings have identified rates of potentially inappropriate medication use according to the Beers criteria and the impact of such inappropriate use on various outcomes, to the authors' knowledge this is the first to examine the effect of these drugs on the risk of injurious falls in an acute care setting in Canada. The current findings do not support use of the Beers criteria for benzodiazepines alone in identifying patients at risk of falls or fall-related injuries. However, further research to determine the effect of potentially inappropriate medications (as defined by the Beers criteria) on other adverse outcomes, as well as research examining barriers to appropriate prescribing, should help to strengthen the empirical evidence for these criteria.

\section{References}

1. Centers for Disease Control and Prevention. Fatalities and injuries from falls among older adults-United States, 1993-2003 and 2001-2005. MMWR Morb Mortal Wkly Rep 2006;55(45):1221-1224.

2. Scott VJ, Dukeshire S, Gallagher EM, Scanlan A. A best practices guide for the prevention of falls among seniors living in the community. Ottawa $(\mathrm{ON})$ : Health Canada, Division of Aging and Seniors; 2001.

3. Tinetti ME, Williams CS. Falls, injuries due to falls, and the risk of admission to a nursing home. N Engl J Med 1997;337(18):1279-1284.

4. Tinetti ME, Williams CS. The effect of falls and fall injuries on functioning in community-dwelling older persons. J Gerontol A Biol Sci Med Sci 1998;53(2):M112-M119.

5. Creditor MC. Hazards of hospitalization of the elderly. Ann Intern Med 1993;118(3):219-223.

6. Vassallo M, Sharma JC, Allen SC. Characteristics of single fallers and recurrent fallers among hospital in-patients. Gerontology 2002;48(3):147-150.

7. Hartikainen S, Lonnroos E, Louhivuori K. Medication as a risk factor for falls: critical systematic review. J Gerontol A Biol Sci Med Sci 2007;62(10):1172-1181.

8. Oliver D, Daly F, Martin FC, McMurdo MET. Risk factors and risk assessment tools for falls in hospital in-patients: a systematic review. Age Ageing 2004;33(2):122-130.

9. Leipzig RM, Cumming RG, Tinetti ME. Drugs and falls in older people: a systematic review and meta-analysis: I. Psychotropic drugs. J Am Geriatr Soc 1999; 47(1):30-39.

10. Monane M, Avorn J. Medications and falls: causation, correlation and prevention. Clin Geriatr Med 1996;12(4):847-858.

11. Page RL 2nd, Ruscin JM. The risk of adverse drug events and hospitalrelated morbidity and mortality among older adults with potentially inappropriate medication use. Am J Geriatr Pharmacother 2006;4(4):297-305.

12. McLeod PJ, Huang AR, Tamblyn RM, Gayton DC. Defining inappropriate practices in prescribing for elderly people: a national consensus panel. CMAJ 1997;156(3):385-391.

13. Beers $\mathrm{MH}$, Ouslander JG. Risk factors in geriatric drug prescribing: a practical guide to avoiding problems. Drugs 1989;37(1):105-112.

14. Hanlon JT, Schmader KE, Ruby CM, Weinberger M. Suboptimal prescribing in older inpatients and outpatients. J Am Geriatr Soc 2001;49(2):200-209.

15. Statement on monitoring drug therapy in the elderly. Ottawa $(\mathrm{ON})$ : Canadian Society of Hospital Pharmacists; 2001 [cited 2008 Jun 30]. Available from: http://www.cshp.ca/dms/dmsView/2_23-Stmt.pdf

16. Beers MH, Ouslander JG, Rollingher I, Reuben DB, Brooks J, Beck JC. Explicit criteria for determining inappropriate medication use in nursing home residents. Arch Intern Med 1991;151(9):1825-1832.

17. Fick DM, Cooper JW, Wade WE, Waller JL, Maclean JR, Beers MH. Updating the Beers criteria for potentially inappropriate medication use in older adults: results of a US consensus panel of experts. Arch Intern Med 2003; 163(22):2716-2724.

18. Passaro A, Volpato S, Romagnoni F, Manzoli N, Zuliani G, Fellin R. Benzodiazepines with different half-life and falling in a hospitalized population: the GIFA study. J Clin Epidemiol 2000;53(12):1222-1229.

19. Diagnosis typing: current Canadian and international practices. Background paper for the development of the ICD-10-CA/CCI acute care inpatient grouping methodology. Ottawa (ON): Canadian Institute for Health Information; 2004 [cited 2008 Dec 1]. Available from: http://www.cihi.ca/ cihiweb/en/downloads/Diagnosis_Typing_Background_v1.pdf 
20. Canadian coding standards for ICD-10-CA and CCI. Ottawa (ON): Canadian Institute for Health Information; 2007 [cited 2008 Dec 1] Available from: http://secure.cihi.ca/cihiweb/dispPage.jsp?cw_page= codingclass_icd10_e\#code

21. Hitcho EB, Krauss MJ, Birge S, Claiborne Dunagan W, Fischer I, Johnson $S$, et al. Characteristics and circumstances of falls in a hospital setting: a prospective analysis. J Gen Intern Med 2004;19(7):732-739.

22. Morse JM. Enhancing the safety of hospitalization by reducing patient falls. Am J Infect Control 2002;30(6):376-380.

23. Nurmi-Lüthje I, Kaukonen JP, Lüthje P, Naboulsi H, Tanninen S, Kataja $\mathrm{M}$, et al. Use of benzodiazepines and benzodiazepine-related drugs among 223 patients with an acute hip fracture in Finland: comparison of benzodiazepine findings in medical records and laboratory assays. Drugs Aging 2006;23(1):27-37.

24. Tamblyn R, Abrahamowicz M, du Berger R, McLeod P, Bartlett G. A 5-year prospective assessment of the risk associated with individual benzodiazepines and doses in new elderly users. J Am Geriatr Soc 2005; 53(2):233-241.

25. Ebly EM, Hogan DB, Fung TS. Potential adverse outcomes of psychotropic and narcotic drug use in Canadian seniors. J Clin Epidemiol 1997;50(7):857-863.

26. Onder G, Landi F, Liperoti R, Fialova D, Gambassi G, Bernabei R. Impact of inappropriate drug use among hospitalized older patients. Eur J Clin Pharmacol 2005;61(5-6):453-459.

27. Crownover BK, Unwin BK. Implementation of the Beers criteria: sticks and stones-or throw me a bone. J Manag Care Pharm 2005;11(5): 416-417.

28. Jano E, Aparasu RR. Healthcare outcomes associated with Beers' criteria: a systematic review. Ann Pharmacother 2007;41(3):438-447.

29. Spinewine A, Schmader KE, Barber N, Hughes C, Lapane KL, Swine C, et al. Appropriate prescribing in elderly people: how well can it be measured and optimised? Lancet 2007;370(9582):173-184.

30. Fu AZ, Liu GG, Christensen DB. Inappropriate medication use and health outcomes in the elderly. J Am Geriatr Soc 2004;52(11):1934-1939.

31. Oliver D, Hopper A, Seed P. Do hospital fall prevention programs work? A systematic review. J Am Geriatr Soc 2000;48(12):1679-1689.
Stacy Ackroyd-Stolarz, BSc(OT), PhD, is with the Department of Emergency Medicine, Dalhousie University, Halifax, Nova Scotia. She is a Postdoctoral Fellow with the College of Pharmacy at Dalhousie University and is the recipient of the Dr David Rippey Patient Safety Fellowship (Canadian Patient Safety Institute and Canadian Institutes of Health Research).

Neil J MacKinnon, PhD, FCSHP, is Associate Director for Research and Professor with the College of Pharmacy, Dalhousie University, Halifax, Nova Scotia. He is cross-appointed to the university's School of Health Administration and Department of Community Health and Epidemiology.

Ingrid Sketris, PharmD, MPA(HSA), is a Professor with the College of Pharmacy, Dalhousie University, Halifax, Nova Scotia. She is crossappointed to the university's School of Nursing, School of Health Administration, Faculty of Computer Science, and Department of Community Health and Epidemiology.

Brenda Sabo, RN, BA, MA, is an Assistant Professor with the School of Nursing, Dalhousie University, Halifax, Nova Scotia. She is also a doctoral candidate in the School of Nursing at Dalhousie University.

\section{Address correspondence to:}

Dr Stacy Ackroyd-Stolarz

Dalhousie University

Emergency Medicine

QEII HSC-Halifax Infirmary

Suite 355

1796 Summer Street

Halifax NS B3H 3A7

\section{Acknowledgments}

Dr Ingrid Sketris holds a chair in drug use management and policy funded by the Canadian Institutes of Health Research and the Canadian Health Services Research Foundation, and cosponsored by the Nova Scotia Health Research Foundation. Stacy Ackroy-Stolarz received salary support as a resident under this chairship.

The authors also acknowledge invaluable assistance from staff in the Pharmacy Department (particularly Heather Lummis, BScPharm, MSc), Quality and Decision Support, and Risk Management at the Queen Elizabeth II Health Sciences Centre, for acquisition of the data, and Sean Higgins, BSc, of the College of Pharmacy, Dalhousie University, for his review of the manuscript before submission. 